\title{
Measuring the Effectiveness of a Proposed Educational Program in Teaching Pattern-Making of Children's Clothing to Severely Hearing-Impaired Students Using E-Learning
}

\author{
Afra Al Liati, Maha Al-Dabagh \\ Fashion and Textile Section, King Abdulaziz University, Jeddah, KSA \\ Email: afraa2009@gmail.com, mdabbaghs@gmail.com
}

How to cite this paper: Al Liati, A., \& Al-Dabagh, M. (2021). Measuring the Effectiveness of a Proposed Educational Program in Teaching Pattern-Making of Children's Clothing to Severely Hearing-Impaired Students Using E-Learning. Open Journal of Social Sciences, 9, 18-41.

https://doi.org/10.4236/jss.2021.912002

Received: October 18, 2021

Accepted: December 4, 2021

Published: December 7, 2021

Copyright $\odot 2021$ by author(s) and Scientific Research Publishing Inc. This work is licensed under the Creative Commons Attribution International License (CC BY 4.0).

http://creativecommons.org/licenses/by/4.0/

\begin{abstract}
Severely hearing-impaired students are among student groups that are most in need of e-learning, as they rely mainly on the sense of sight when receiving information. Therefore, teachers are advised to activate the use of new technologies to overcome the academic difficulties and problems they face. That said, this study aimed to prepare a proposed educational program using e-learning for the severely hearing-impaired students in the (fashion manufacturing) course at the Faculty of Human Sciences and Designs of King Abdulaziz University. The study also sought to measure the program effectiveness in imparting basic knowledge and skills on (pattern-making of children's clothing) to the research sample, using e-learning. The study applied the descriptive approach so as to address the research theoretical framework, and to determine the basic knowledge on methods that are utilized in preparing electronic curricula, in consistent with the cognitive, educational and emotional characteristics of severely hearing-impaired students, as well as to address the basic knowledge of the (children's clothing) curriculum. It also applied the experimental approach to measure the effectiveness of the proposed educational program in imparting basic knowledge of the pattern-making of children's clothing. The study sample included 21 severely hearing-impaired students, who are studying fashion manufacturing course within a bachelor's program. The study tools included an evaluation form to be filled by expert assessors in the field of fashion and textiles as well as specialists in hearing impairment, on the effectiveness of the proposed educational program in imparting basic knowledge and skills of pattern-making of children's cloth-
\end{abstract}


ing. It also included achievement posttests and pretests to measure the effectiveness of the proposed educational program in imparting knowledge to the students, and cognitive posttests and pretests to measure the program's effectiveness in imparting skills to the students. The tools also included a skill performance assessment scale to measure the students' attitudes towards the proposed educational program, using e-learning. The study found that there was a statistically significant difference at the level (0.05) between the frequencies and percentages of the levels of students' attitudes towards learning pattern-making of children's clothing using e-learning, which confirms the effectiveness of the proposed educational course. The research recommends that computer-based educational programs be applied to the other courses in fashion and textile section, and to be designed in a way that considers the characteristics of severely hearing-impaired students.

\section{Keywords}

Educational Program, E-Learning, Severely Hearing-Impaired Students, Fashion Manufacturing

\section{Introduction}

Nowadays, attention to education has imposed itself as a necessity, given its effective contribution in supporting the success of economic and social development plans that aim to improve the living standards, since the progress and advancement of nations are measured by the extent of its industrial technological progress, in which education plays a key role (Jabr, 2012).

People with hearing impairment are partners in development process, and they have the right to education like their non-disabled peers. Saudi Arabia's national strategy for the development of public education has emphasized the importance of providing equal learning opportunities and support systems for all students, by means of providing equal enrollment opportunities and equal and appropriate education in schools and universities for students with special needs (Ministry of Education, 2021).

King Abdulaziz University takes part in implementing this national strategy by launching an initiative to avail a bachelor's degree for students with severe hearing impairment at the College of Human Sciences and Design, in the Fashion and Textiles section, Fashion Manufacturing course.

The program targets graduates of the Al-Amal Secondary Institute and female students with severe hearing impairment, with the aim to provide an equal educational environment for severely hearing-impaired students that enables them to study along other students in the community, while availing them the opportunity to obtain a university degree in the fashion industry so as to empower them and enable them to be competitive in the labor market, in line with the National Transformation Program 2030, which aims to include students with spe- 
cial needs in the education process, and to provide adequate support for them.

Modern trends in educating students with special needs agree that people with different impairments, including severely hearing-impaired students, have abilities and potentials that are no less than normal people, provided that an educational environment be provided to them, to contribute to achieving the desired goals of their upbringing and education (Hanafi, 2018), and to enable them to compete with other disability-free students and show the same educational and professional skills. Severely hearing-impaired students are expected to be creative, since hearing disability does not mean that those students are mentally deficient. However, the performance of severely hearing-impaired students may be lower than that of disability-free students in the IQ-tests due to the delay in language development (Al-Nimr, 2015: pp. 80-81).

Hanafi (2009) indicated that they lack language skills compared to their peers, which leads to a significant decrease in their linguistic wealth, delayed language development, reading ability and comprehension. Moreover, other characteristics may affect their level of achievement, as mentioned by Al-Shehri (2019) such as their rapid boredom and moodiness, low level of reading comprehension, difficulty paying attention and focusing on a topic for a long period of time, or when they shift from one topic to another. Such characteristics lead to a slowed learning process, because they rely on the sense of sight alone in understanding and comprehending things.

Perhaps such characteristics lead to an inability to integrate with the society and a decreased academic achievement. Therefore, educational institutions need to find proper solutions, and choose the best means and modern educational techniques to help those students raise their level of academic achievement, by means of utilizing e-learning; which recently has become a field of interest to educational institutions and authorities in all different spheres of education.

Students with hearing impairment are most in need of using e-learning, as they rely mainly on the sense of sight when receiving information (Al-Gabr, 2019). This fact requires teachers to activate the use of modern technologies to solve the academic difficulties and problems they face.

Ayasra (2017) emphasized that e-learning takes into account the most important characteristics of students with hearing impairments, such as their different abilities in understanding and their need to repeat information visually to keep and preserve the information. E-learning, meanwhile, enables such students to access various programs easily through available electronic links, thus the learning process becomes easy, accessible, more enjoyable and attractive for them.

From this point of view, this study aimed to prepare a proposed educational program using e-learning system in teaching (pattern-making of children's clothing curriculum) to students with severe hearing impairments.

\section{The Research Problem}

The rationale of carrying out this research stems from the lack of an electronic educational tool for students with severely hearing impairment. 
The Research problem lies in the lack of e-learning programs for students with hearing impairment, that is compatible with their mental, cognitive and psychological abilities and capabilities. Thus, the current study sought to prepare a proposed educational program using an e-learning system to teach the course of pattern-making of children's clothing to students with severe hearing impairment; a curriculum intended for students with severe hearing impairment, who are studying fashion manufacturing major under the Bachelor's Program at the Faculty of Humanities and Designs, Clothing and Textiles Section of King Abdulaziz University.

The Research problem can be summarized in the following questions:

How possible it is to prepare an educational program on pattern-making of children's clothing for the severely hearing-impaired students using e-learning?

What is the effectiveness of the proposed educational program on pattern-making of children's clothing in developing the cognitive and skill performance of students with severe hearing impairment?

What are the emotional and cognitive attitudes of female students enrolled in the program at King Abdulaziz University towards the proposed educational program?

\section{Study Objectives}

- Prepare a proposed educational program on (pattern-making of children's clothing) using e-learning for students with severe hearing impairments, to be delivered within the fashion manufacturing course under the Bachelor's Program provided at the Faculty of Human Sciences and Designs of King Abdulaziz University.

- Measure the effectiveness of the proposed educational program in imparting knowledge and skills on pattern-making of children's clothing to the research sample.

- Measure the cognitive and emotional attitudes of the hearing-impaired students in learning (pattern-making of children's clothing) using e-learning.

\section{Research Significance}

- This research seeks to use modern technology to provide different methods that are compatible with and appropriate for students with severe hearing impairment.

- It helps achieve Saudi Vision 2030 by providing a university degree for students with severe hearing impairment, that would allow them to receive job opportunities appropriate to their skills and inclinations, and that would enable them to become productive and self-sufficient.

- It cultivates and instills self-confidence in students with severe hearing impairment by making them realize their potentials to perform, as well as by developing their professional skills. 


\section{Research Hypothesis}

- There is a statistically significant difference at level $(\alpha \leq 0.05)$ between the mean scores of students in the experimental group after the application of pretests and posttests on the cognitive achievement, in favor of posttests.

- There is a statistically significant difference at level $(\alpha \leq 0.05)$ between the mean scores of students in the experimental group after the application of pretests and posttests on skill performance, in favor of posttests.

- There is a statistically significant difference at level (0.05) between the frequencies and percentages of the levels of the attitude scale of students with severe hearing impairment towards learning pattern-making of children's clothing, using e-learning (strongly agree, agree, neutral, disagree, strongly disagree).

- There is a positive significant correlation between the scores of students in the experimental group in the cognitive achievement posttests and their scores on the skill performance test.

- Providing an educational program in pattern-making of children's clothing for students with severe hearing impairment using e-learning, can be effective in developing cognitive achievement and skill performance, according to Blake Modified Gain Ratio.

\section{Research Methodology and Procedures}

- The descriptive approach: To address the theoretical framework of the research, and to determine the basic knowledge on methods of preparing electronic curricula that suit the cognitive, educational and emotional characteristics of students with severe hearing impairment, as well as to address the basic knowledge of the (children's clothing) curriculum.

- The experimental approach: To measure the effectiveness of the proposed educational program in imparting basic knowledge and skills as outlined in the (pattern-making of children's clothing) curriculum, in a manner that is consistent with the educational, cognitive and emotional characteristics of students with severe hearing impairment who are studying fashion manufacturing course under the bachelor's program.

\subsection{Research Tools}

- An evaluation form to be presented to expert assessors in the field of fashion and textiles as well as to specialists in hearing impairment, to appraise the potential of the proposed program to impart basic knowledge and skills on (pattern-making of children's clothing).

- Achievement pretests and posttests to measure the effectiveness of the proposed program in imparting basic knowledge and skills.

- Cognitive pretests and posttests to measure the effectiveness of the proposed program in imparting basic knowledge and skills.

- Skill Performance Assessment Scale. 
- An Assessment Form to measure the attitudes of students with hearing impairment towards the proposed educational program, using e-learning.

\subsection{Research Delimitations}

- Objective limits: The basic knowledge of the (children's clothing) curriculum, in addition to the basic knowledge of organizing electronic educational content, in a manner that suits students with hearing impairment, and its application and production using Hypermedia and Multimedia technology in the form of an interactive e-book.

- Spatial limits: King Abdulaziz University, College of Human Sciences and Designs, Fashion and Textile Section, Bachelor's Program, major of Fashion Manufacturing for the severely hearing-impaired students.

- Human limits: Students enrolled in the Bachelor of Fashion and Textiles, (Fashion Manufacturing course) for the severely hearing-impaired students.

\subsection{Research Sample}

- All female students (21) enrolled in the Bachelor of Fashion and Textiles, Fashion Manufacturing course, for the severely hearing-impaired students, level two.

- Experimental design of the research.

- This research has applied the experimental approach, in which the research's tools were applied on the sample before the introduction of the proposed program, and then applied again after introducing the sample to the proposed educational program, with the aim to identify the effectiveness of the proposed educational program in imparting basic knowledge on pattern-making of children's clothing.

\section{Research Terms}

- Educational programs: A computer-designed educational unit set in a coherent and organized manner according to sound educational foundations that includes a set of knowledge, experiences, activities, methods and various assessment methods based on the principle of response and reinforcement that seeks to achieve specific educational goals (Al-Hawali, 2010: p. 7).

- People with hearing impairment: (Medical definition) It is a defect in ear's efficiency to perform its normal auditory function, and this defect may be a complete hearing disability (deafness), or it may be a partial disability (hearing impairment) (Al-Khasawneh et al., 2010).

- E-learning: It is a method of education in which modern communication tools such as computers, networks, multimedia, including sound, image, graphics, research mechanisms and electronic libraries, as well as internet portals, whether in distance learning or in the classroom, are used to achieve the aspired results in the shortest time, with the least effort, and the greatest benefit (Fares \& Ismail, 2017: p. 31). 


\section{Research Procedures}

In light of the general procedural goals and the content of the proposed educational program, literature review, educational theses, research and previous studies related to an educational program for students with severe hearing impairment in pattern-making of children's clothing, using e-learning, were used in building and designing the research tools and materials, including the cognitive test, the skill performance test, the skill assessment scale, and an attitude scale of students with severe hearing impairment towards learning the pattern-making of children's clothing course, using e-learning. The research tools were prepared and designed as follows:

\subsection{Calculating the validity and reliability of the cognitive test}

\section{Validity of the cognitive test:}

The current research relied on two methods to verify the validity of the test:

\section{(a) Content Validity:}

To verify the content's validity, a cognitive test was presented to a number of expert assessors, who are faculty members in the Department of Fashion and Textiles (Fashion manufacturing), at the College of Human Sciences and Designs, King Abdulaziz University, in order to give their opinions on the test in terms of the suitability of the questions in relation to the characteristics of students with hearing impairment, the extent to which the questions are related to the cognitive objectives, the extent to which the test covers the knowledge included in the program, and the clarity of questions. The researcher has received a feedback from both the students and expert assessors and modified some phrases as requested. Thus, the cognitive test can be said to have been subjected to content validity. The following Table 1 shows the agreement coefficient on the cognitive test.

The researcher used the method of agreement of (10) expert assessors in calculating the experts' stability in determining the assessment items to be

Table 1. Coefficient of the experts' agreement on the cognitive test.

\begin{tabular}{lccc}
\hline \multicolumn{1}{c}{ Arbitration clauses } & $\begin{array}{c}\text { Number } \\
\text { of times of } \\
\text { agreement }\end{array}$ & $\begin{array}{c}\text { Number of } \\
\text { times of } \\
\text { non-agreement }\end{array}$ & $\begin{array}{c}\text { Coefficient } \\
\text { of } \\
\text { agreement }\end{array}$ \\
\hline $\begin{array}{l}\text { The suitability of the questions for the } \\
\text { characteristics of the hearing-impaired } \\
\text { students }\end{array}$ & 10 & 0 & $100 \%$ \\
$\begin{array}{l}\text { The extent to which the questions relate } \\
\text { to the cognitive objectives }\end{array}$ & 9 & 1 & $90 \%$ \\
$\begin{array}{l}\text { Extent of the test coverage of the } \\
\text { knowledge included in the program }\end{array}$ & 8 & 2 & $80 \%$ \\
$\begin{array}{l}\text { Clarity of the language of the questions } \\
\text { so that they are easy to understand }\end{array}$ & 9 & 1 & $90 \%$ \\
\hline
\end{tabular}


implemented, provided that each of them records his observations independently of the other. The number of times of agreement between the assessors was determined using the Cooper equation: agreement percentage $=($ Number of times of agreement + number of times of disagreement) $) \times 100$. The percentage of agreement was (100\%), which is high and acceptable agreement rates.

(b) The validity of the internal consistency:

The test was applied on a sample of (5) students from the Department of Fashion and Textiles, College of Human Sciences and Designs, King Abdulaziz University (specializing in fashion manufacturing), and after the application, the validity of the items was calculated using the Cronbach Alpha coefficient, which is a high coefficient of stability. The following Table 2 shows the Pearson correlation coefficients between the sub-items and the scale as a whole:

By extrapolating the previous table, it becomes clear that all the correlation coefficients between each item and the test (as a whole) are strong direct correlation coefficients, and are significant at the 0.01 level. Based on the above, these results indicate that the sub-items have a high degree of internal consistency.

\section{Stability of Cognitive test:}

To calculate the stability of the test, the application was applied on a sample of (5) students from the Department of Fashion and Textiles at the College of $\mathrm{Hu}$ man Sciences and Designs at King Abdulaziz University (specializing in fashion manufacturing), and after the application, the stability was calculated by the reapplication method.

\section{Reapplication method:}

The reliability coefficient of the test was calculated using the reapplication method. The researcher applied the measurements to a sample of (5) female students, then the test was re-applied again after a three-week interval. The researcher used the SPSS21 statistical package, version 21, to calculate the correlation coefficient. The reliability coefficient of the test as a whole was (0.856), which is a high stability coefficient, and therefore the test results can be said to be reliable, and can also be relied upon as research tools.

Calculate the reliability of the test using a split-half:

In this method, the scale is applied once, then it is divided into two equal halves, and the correlation coefficient between the scores of these two halves is

Table 2. Pearson correlation coefficients between sub-items and the scale (as a whole) for the cognitive achievement test.

\begin{tabular}{cccccc}
\hline Item & $\begin{array}{c}\text { correlation } \\
\text { coefficients }\end{array}$ & Item & $\begin{array}{c}\text { correlation } \\
\text { coefficients }\end{array}$ & Item & $\begin{array}{c}\text { correlation } \\
\text { coefficients }\end{array}$ \\
\hline 1 & $0.851^{\star *}$ & 6 & $0.813^{\star *}$ & 11 & $0.815^{\star *}$ \\
2 & $0.822^{\star *}$ & 7 & $0.862^{\star *}$ & 12 & $0.831^{\star *}$ \\
3 & $0.843^{\star *}$ & 8 & $0.840^{\star *}$ & 13 & $0.753^{\star *}$ \\
4 & $0.833^{\star *}$ & 9 & $0.835^{\star *}$ & 14 & $0.855^{\star *}$ \\
5 & $0.853^{\star *}$ & 10 & $0.822^{\star *}$ & & \\
\hline
\end{tabular}


calculated, and then the test reliability coefficient is predicted.

It is clear that the overall stability coefficient of the test by Spearman/Brown's half-split method is equal to (0.855) when the two test halves are equal, and equal to (0.855) in unequal halves. In addition, the overall stability coefficient of the test by Guttmann' Split Half is equal to (0.859), which indicates a high overall stability coefficient. Based on the foregoing, the test in its final form consists of (14) items (Table 3).

\section{Cognitive achievement test time:}

The time of the test was estimated in light of the observations, and by means of monitoring the students' performance. The test time was (30) minutes.

Ease and difficulty coefficients for the items of the cognitive achievement test:

The coefficient of ease and difficulty was calculated by applying the following two equations:

The coefficient of ease was calculated by applying the following Equation: Paragraph Ease coefficient $=\frac{\text { The number of students who answered correctly }}{\text { The number of students who answered the question }}$

The difficulty coefficient was calculated by applying the following Equation:

$$
\begin{aligned}
& \text { Paragraph difficulty factor } \\
& =\frac{\text { The number of students who answered correctly }}{\text { The number of students who answered the question }}
\end{aligned}
$$

That is, the coefficient of difficulty $=1$ is the coefficient of ease, and thus the coefficients of difficulty for the test items ranged between $(0.345-0.861)$. It was concluded that the test items were of medium difficulty compared to the level of students, while the ease coefficients of the test items ranged between $(0.227$ 0.845 ) and are explained as not very difficult, and therefore the number of test items remained 14 without any change.

Coefficient of discrimination for the items of the cognitive achievement test:

Coefficients of discrimination were calculated and ranged between (0.385:0.832), and thus the test items are considered to have an appropriate ability to differentiate.

Putting the cognitive achievement test in the final form for application:

After calculating the statistical coefficients, the cognitive achievement test assumed its final form. The test included three questions:

Table 3. The total stability coefficient using split half of spearman/brown, and Gottman.

\begin{tabular}{ccc}
\hline \multirow{2}{*}{ Gottman } & \multicolumn{2}{c}{ Spearman/Brown } \\
\cline { 2 - 3 } & $\begin{array}{l}\text { If the test halves are not } \\
\text { equal-Unequal length }\end{array}$ & $\begin{array}{l}\text { If the test halves are } \\
\text { equal_Equal Length }\end{array}$ \\
\hline 0.859 & 0.855 & 0.855 \\
\hline
\end{tabular}


The first question was comprised of (8) statements, and the student was required to place a check mark $(\sqrt{ })$ in front of the correct statement and a check mark $(x)$ in front of the wrong one: The first question was of ( 8 marks); a mark for each statement.

The second question was comprised of two groups: the first group contained terminology on some needs of infants, while the second group contained pictures corresponding to these terms: The student was required to put the appropriate term next to the corresponding picture? The maximum score for the test was (14), and a standard rubric was established, thus the test was validated and ready to be applied in its final form.

\subsection{Skill Performance Test}

The aim of the test was to measure the extent to which students with severe hearing impairment can acquire the skills for pattern-making of children's clothing, using e-learning.

\section{Drafting of items of skill assessment scale:}

The skill performance test was constructed, and was comprised of (3) axes, each containing (18 items) by which the skill level of students with severe hearing impairment in pattern-making of children's clothing, using e-learning, can be measured. The students' responses to them are measured according to 3 Point Likert scale. The following Table 4 shows the number of items that fall under each axis of the skill performance test.

\section{Marking:}

The skill test was marked by a tripartite committee of specialists in the Department of Fashion and Textiles at the College of Human Sciences and Designs-King Abdulaziz University. The criteria for evaluating the student's achievement of the skill were set at three levels as follows:

1) It indicates good skill performance.

2) It indicates very good skill performance

3) Indicates excellent skill performance.

\section{Validation of the skill performance test:}

To ensure the validity of the scale, it was presented in its initial form to a group of 10 expert assessors in the field of "Fashion and Textiles", to give their

Table 4. Skill performance test axes.

\begin{tabular}{lc}
\multicolumn{1}{c}{ Axles } & Number of axes items \\
\hline The basic divisions of the pattern & 1 \\
Pattern drawing & 7 \\
Data writing within the borders of the pattern & 6 \\
Color the basic lines of the pattern as per the & \\
colors assigned to them & 20 \\
Total & \\
\hline
\end{tabular}


views on the clarity of the items and the validity of its linguistic phrasing, and to identify the items' ability to measure the students' skill performance. The following Table 5 shows the percentages of agreement between the assessors on the items of the skill performance test.

It is clear from the previous table that the experts' agreement coefficient with respect to the skill performance test was ( $90 \%$ to $100 \%$ ), which indicates the experts' validity.

\section{Calculating the validity of internal consistency:}

The validity of the item was calculated using the Cronbach Alpha method. The total reliability and validity of the item were calculated. The total stability coefficient and the validity of the item is equal to (0.876), which is a high stability coefficient. Based on the foregoing, these results indicate that the item has a high degree of internal consistency.

\section{Calculating the stability of the skill assessment scale:}

The reliability of the scale was calculated using Half-Split method. This method entails the application of the test once and then splitting it into two equal halves, and the correlation coefficient between the scores of these two halves is calculated, and then the scale reliability coefficient is predicted. The Spearman/Brown Half-Split is (0.873) when the two halves of the scale are of equal length and when the two halves of the scale are not equal. In addition, the overall stability coefficient of the scale in the Gottman Half-Split method is equal to (0.877), which indicates a high overall stability coefficient of the scale (as a whole).

It is clear from the previous Table 6 that the values of the stability coefficient of the dimensions and the scale are significant at the level of (0.01), which confirms the stability of the skill performance test, and it can also be relied upon as a research tool.

Table 5. Assessors' agreement coefficient on items of the skill performance test.

\begin{tabular}{|c|c|c|c|}
\hline $\begin{array}{c}\text { Number of items to be } \\
\text { evaluated }\end{array}$ & $\begin{array}{c}\text { The number of } \\
\text { times of } \\
\text { agreement }\end{array}$ & $\begin{array}{c}\text { The number of } \\
\text { times of } \\
\text { disagreement }\end{array}$ & $\begin{array}{c}\text { The coefficient of } \\
\text { agreement }\end{array}$ \\
\hline $\begin{array}{l}\text { The extent to which } \\
\text { the test relates to the } \\
\text { skill objectives of the } \\
\text { program }\end{array}$ & 10 & 0 & $100 \%$ \\
\hline $\begin{array}{l}\text { The extent to which } \\
\text { the test covers the } \\
\text { knowledge included in } \\
\text { the program }\end{array}$ & 9 & 1 & $90 \%$ \\
\hline $\begin{array}{l}\text { Clarity of the language } \\
\text { of the questions so that } \\
\text { they are easy to } \\
\text { understand }\end{array}$ & 10 & 0 & $100 \%$ \\
\hline
\end{tabular}


Table 6. Stability coefficients for the skill performance test on each of the axes.

\begin{tabular}{lc}
\hline \multicolumn{1}{c}{ The axis } & Alpha coefficient \\
\hline The basic divisions of the pattern & $0.866^{\star *}$ \\
pattern drawing & $0.862^{\star *}$ \\
Data writings within the borders of the pattern & $0.866^{\star *}$ \\
Color the basic lines of the pattern as per the colors & $0.873^{\star *}$ \\
assigned to them & \\
\hline
\end{tabular}

\section{Putting the skill performance test into final form for application:}

After calculating the statistical parameters, the skill performance test assumed its final form as it included (20) indicators, and the maximum score was (60) as shown in Table 7 below:

Thus, the test is valid and ready for application in its final form.

\subsection{Skill Performance Assessment Scale}

The assessment scale aims to build an objective tool for evaluating the skill performance through the designs implemented by the students in both the pretests and posttests to measure the effectiveness of a blended-learning style book in teaching modern techniques of shaping on mannequin. It is a form that contains the items to be evaluated and a measure of the level of performance.

Drafting of items of skill performance assessment scale:

The skill performance assessment scale was built, and it included (3) axes comprised of (18 items) by which the level of skill performance of students with severe hearing impairment in pattern-making of children's clothing, using e-learning, is measured. The students' responses to them are measured according to 3 Point Likert scale. The following Table 8 shows the number of items that fall under each axis of the skill performance assessment scale.

\section{Marking:}

The skill test was marked by a tripartite committee of specialists in the Department of Fashion and Textiles at the College of Human Sciences and Designs-King Abdulaziz University, by placing the grade mark that applies to each item of the skill performance assessment scale that are included in the test, and then translating the scores into grades.

The criteria for evaluating the student's achievement of the skill were set at three levels as follows:

1) Indicates good performance of the skill.

2) It indicates very good performance

3) Indicates excellent performance.

\section{Validation of the skill performance assessment scale:}

To ensure the validity of the scale, it was presented in its initial form to a group of 10 expert assessors in the field of "Fashion and Textile", so as to give their views on the clarity of the items, the validity of their linguistic phrasing, and identify the items' ability to measure the skill performance of students. The 
Table 7. The maximum score for the skill performance test (as a whole) and for each of the axes.

\begin{tabular}{lccc}
\hline \multicolumn{1}{c}{ The axis } & $\begin{array}{c}\text { Number of } \\
\text { phrases }\end{array}$ & $\begin{array}{c}\text { Minimum } \\
\text { degree }\end{array}$ & $\begin{array}{c}\text { Maximum } \\
\text { degree }\end{array}$ \\
\hline $\begin{array}{l}\text { The basic divisions } \\
\text { of the pattern }\end{array}$ & 1 & 1 & 1 \\
pattern drawing & 7 & 7 & 21 \\
$\begin{array}{l}\text { Data writings within the } \\
\text { borders of the pattern }\end{array}$ & 6 & 6 & 8 \\
$\begin{array}{l}\text { Color the basic lines of } \\
\text { the pattern as per the } \\
\text { colors assigned to them }\end{array}$ & 6 & 6 & 18 \\
\begin{tabular}{l} 
Total \\
\hline
\end{tabular} & 20 & 20 & 60 \\
\hline
\end{tabular}

Table 8. Axes of the skill performance scale.

\begin{tabular}{lc}
\multicolumn{1}{c}{ Axles } & The number of axes items \\
\hline The basic divisions of the pattern & 1 \\
pattern drawing & 6 \\
Data writings within the borders of the pattern & 6 \\
Color the basic lines of the pattern as per & 20 \\
the colors assigned to them & \\
Total &
\end{tabular}

following Table 9 shows the percentages of agreement between the assessors on the items.

It is clear from the previous table that the assessors' agreement coefficient in relation to the skill performance assessment scale was (100\%), which indicates that the skill performance assessment scale was highly validated by the assessors.

\section{Calculating the validity of internal consistency:}

The validity of the item was calculated using the Cronbach Alpha method. The total reliability and validity of the item were calculated. The total stability coefficient and the validity of the item is equal to (0.792), which is a high stability coefficient. The following Table 10 shows the Pearson correlation coefficients between the sub-indicators and the scale as a whole:

By extrapolating the previous table, it is clear that all the correlation coefficients between each item and the scale as a whole are strong direct correlation coefficients, which are significant at the 0.01 level. Based on the above, these results indicate that the sub-items enjoy a high degree of internal consistency.

Calculating the stability of the skill assessment scale:

The reliability of the scale was calculated using Half-Split method. This method entails the application of the test once and then splitting it into two equal halves, and the correlation coefficient between the scores of these two halves is 
Table 9. Assessors' agreement coefficient on the items of the skill performance assessment scale.

\begin{tabular}{|c|c|c|c|}
\hline Items to be evaluated & $\begin{array}{c}\text { The number of } \\
\text { times of } \\
\text { agreement }\end{array}$ & $\begin{array}{c}\text { The number of } \\
\text { times of } \\
\text { disagreement }\end{array}$ & $\begin{array}{c}\text { The coefficient } \\
\text { of agreement }\end{array}$ \\
\hline $\begin{array}{l}\text { The suitability of the } \\
\text { assessment scale to } \\
\text { efficiently assess the } \\
\text { skill performance of } \\
\text { the student }\end{array}$ & 10 & 0 & $100 \%$ \\
\hline $\begin{array}{l}\text { The extent to which the } \\
\text { assessment scale covers } \\
\text { all the skills required } \\
\text { to be implemented in } \\
\text { the skill test }\end{array}$ & 10 & 0 & $100 \%$ \\
\hline $\begin{array}{l}\text { Validity of the linguistic } \\
\text { phrasing }\end{array}$ & 10 & 0 & $100 \%$ \\
\hline
\end{tabular}

Table 10. Pearson correlation coefficients between sub-items and skill performance scale.

\begin{tabular}{|c|c|c|c|c|c|}
\hline $\begin{array}{c}\text { Pearson } \\
\text { correlation } \\
\text { coefficient }\end{array}$ & Indicator & $\begin{array}{c}\text { Pearson } \\
\text { correlation } \\
\text { coefficient }\end{array}$ & Indicator & $\begin{array}{c}\text { Pearson } \\
\text { correlation } \\
\text { coefficient }\end{array}$ & Indicator \\
\hline $0.833^{* *}$ & 15 & $0.876^{* *}$ & 8 & $0.852^{\star *}$ & 1 \\
\hline $0.854^{\star *}$ & 16 & $0.789^{\star *}$ & 9 & $0.842^{\star *}$ & 2 \\
\hline $0.817^{\star *}$ & 17 & $0.814^{\star *}$ & 10 & $0.823^{* *}$ & 3 \\
\hline $0.880^{* *}$ & 18 & $0.834^{\star *}$ & 11 & $0.812^{\star *}$ & 4 \\
\hline $0.867^{\star *}$ & 19 & $0.811^{\star *}$ & 12 & $0.837^{\star *}$ & 5 \\
\hline \multirow[t]{2}{*}{$0.733^{\star *}$} & 20 & $0.830^{* *}$ & 13 & $0.860^{* *}$ & 6 \\
\hline & & $0.831^{\star *}$ & 14 & $0.810^{\star *}$ & 7 \\
\hline
\end{tabular}

calculated, and then the scale reliability coefficient is predicted. The Spearman/Brown Half-Split is (0.873) if the two halves of the scale are of equal length and if the two halves of the scale are not equal. In addition, the overall stability coefficient of the scale in the Gottman Half-Split method is equal to (0.877), which indicates a high overall stability coefficient of the scale (as a whole).

It is clear from the previous Table 11 that the values of the stability coefficient of the dimensions and the scale as a whole are significant at the level (0.01), which confirms the stability of the skill performance assessment scale, and that it can be relied upon as a research tool.

Putting the skill performance assessment scale in its final form for application:

After calculating the statistical parameters, the skill performance scale assumed its final form, as the scale included (20) sub-indicators, and the maximum 
Table 11. Stability coefficients for the skill performance test on each of the axes.

\begin{tabular}{lc}
\hline \multicolumn{1}{c}{ The axis } & alpha coefficient \\
\hline The basic divisions of the pattern & $0.865^{* *}$ \\
pattern drawing & $0.859^{* *}$ \\
Data writings within the borders of the pattern & $0.875^{* *}$ \\
$\begin{array}{l}\text { Color the basic lines of the pattern as per the colors } \\
\text { assigned to them }\end{array}$ & $0.876^{* *}$ \\
\hline
\end{tabular}

score for the scale was (60) as shown in Table 12 below.

The scale is thus valid and ready for application in its final form.

\subsection{An Evaluation Form to Measure the Attitudes of Students with Hearing Impairment towards the Proposed Educational Program, Using E-Learning}

After reviewing previous studies, the paragraphs of the attitudes scale were drafted. It included positive statements, and the answer to them was comprised of five possibilities according to the five-point Likert scale, and they range from (strongly agree, agree, neutral, disagree, strongly disagree). The student is given a grade of (5) if she answered the phrase with a rating of "strongly agree", (4) points if she answered "agree", and (3) points if she answered "neutral", two points if she answered "disagree", and a degree of (1) If she answered "strongly disagree".

Calculating the validity of internal consistency:

The validity of the item was calculated using the Cronbach Alpha method. The total reliability and validity of the item were calculated. The total stability coefficient and the validity of the item is equal to (0.910), which is a high stability coefficient. It becomes clear that all the correlation coefficients between each individual item and the scale as a whole are strong direct correlation coefficients, and they are significant at the 0.01 level. Based on the foregoing, these results indicate that the sub-items of the scale of female students' attitudes towards the proposed educational program have a high degree of internal consistency of the scale.

The stability of the attitude scale of students with severe hearing impairment towards learning pattern-making of children clothing, using e-learning:

The reliability of the scale was calculated using Half-Split method. This method entails the application of the test once and then splitting it into two equal halves, and the correlation coefficient between the scores of these two halves is calculated, and then the scale reliability coefficient is predicted. The Spearman/Brown Half-Split is (0.911) if the two halves of the scale are of equal length and if the two halves of the scale are not equal. In addition, the overall stability coefficient of the scale in the Gottman Half-Split method is equal to (0.921), which indicates a high overall stability coefficient of the scale (as a whole). 
Table 12. The maximum score for the skill performance test (as a whole) and for each of the axes.

\begin{tabular}{lccc}
\hline \multicolumn{1}{c}{ The axis } & $\begin{array}{c}\text { Number of } \\
\text { phrases }\end{array}$ & $\begin{array}{c}\text { Minimum } \\
\text { degree }\end{array}$ & $\begin{array}{c}\text { Maximum } \\
\text { degree }\end{array}$ \\
\hline $\begin{array}{l}\text { The basic divisions of } \\
\text { the pattern }\end{array}$ & 1 & 1 & 1 \\
$\begin{array}{l}\text { pattern drawing } \\
\begin{array}{l}\text { Data writings within the } \\
\text { borders of the pattern }\end{array}\end{array}$ & 6 & 7 & 21 \\
$\begin{array}{l}\text { Color the basic lines of the } \\
\text { pattern as per the colors } \\
\text { assigned to them }\end{array}$ & 6 & 6 & 18 \\
Total & 20 & 20 & 60 \\
\hline
\end{tabular}

After calculating the statistical parameters, the attitude scale of students with severe hearing impairment towards learning pattern-making of children clothing's using e-learning was put in its final form. The scale included (10) statements, and the maximum degree of the scale was (50), so the scale became valid and ready for application in its final form.

\section{Building the Proposed Interactive E-Book}

The interactive e-book was prepared based on a specific educational design model, and the current study followed the developed model of Elgazzar (2014), for its compatibility with e-learning innovations. The model consists of five stages illustrated by the following summary:

The following is a detailed presentation of the stages of the interactive e-book which was developed after the model of Abdul Latif Al-Jazzar:

Adopting or setting educational design standards for the
e-learning environment.
Analysis of the basic educational characteristics of the target
through standard needs, content analysis or needs assessment:
Analyzing the available digital resources, the LMS, the LCMS,
the available learning objects, the obstacles and constraints.
The program design phase started with the following steps:
Drafting of educational objectives according to the ABCD
format, based on the needs and inputs and outputs analysis
according to the hierarchy:




\section{Continued}

Design of assessment and tests: Spoken tests, and unit pretests and posttests:

Designing Learning Experiences: Resources and activities, personal or group interaction of learners, opportunities for possible integration, web links, and the role of the teacher, for each objective:

Final selection of alternative multimedia elements for learning experiences for resources and activities

Design storyboards for the selected media and activities

Designing the means of (navigation), learning controllers, and the learner interface

Identification of synchronous and asynchronous communication tools inside and outside the environment

Designing the method of registering learners, managing them, assembling them, and providing them with a support system.

Designing Information, Components, and Forms for E-Learning Environments.

\section{It was divided into sub-stages as follows:}

Access to Media, Resources, Activities and Learning Objects.

Modify output media, resources, activities, and other components.

Converting media elements to digital form and storing them

Producing the e-learning environment model

Uploading or linking the components of the

e-learning environment:

The components of the e-learning environment have been linked in four phases.

The educational program was evaluated in two phases:

\section{First stage: Initial assessment and evaluation}

The initial model of the video clips was presented to 11 students. The videos have been evaluated by four faculty members, two faculty members at King Abdulaziz University, from the Clothing Design and Production Section, and a member from Umm Al-Qura University, and a member of the Technical College for Girls in Jeddah.

Some modifications were proposed, and modified accordingly, and the program final form was assessed and applied on the experimental sample.

The second stage: Evaluating the proposed educational program in its final form 


\section{Continued}

Evaluating the effectiveness of an educational program in
teaching pattern-making of children's clothing for the
severely hearing-impaired students, using e-learning
The educational program in its initial form was presented
and textile", to ensure the linguistic phrasing is sound,
and to evaluate the extent to which the question is linked
of the objectives with the educational program, and to
add any suggested phrases.
environment
e-learning environment

Ten assessors agreed in calculating the assessors' stability in determining the assessment items to be implemented, provided that each of them records his observations independently of the other. The number of times of agreement between the assessors was determined using the Cooper equation: the percentage of agreement $=$ (number of times of agreement/(number of times of agreement + number of times of disagreement)) $\times 100$, and the percentage ranged from $80 \%$ to $100 \%$, which are high and acceptable agreement rates (Table 13).

After analyzing the results of the levels of the assessment form on designing children's clothing models, and implementing them using e-learning, which used 5 Point Likert scale (often, sometimes, rarely, not available, not available at all), the frequencies, percentages and the value of Chi-squared test were calculated to determine the educational program' the suitability to the characteristics of the target group.

It was clear that there are significant differences between the frequencies and percentages between the levels of the assessment form (evaluation of an educational program in pattern-making of children's clothing, using e-learning) in favor of the choice (mostly), which confirms the effectiveness of the program and its suitability for the target group (the severely hearing-impaired students) as an educational system compatible with their characteristics and educational abilities.

\section{Implementation of Basic Experiment:}

The experiment was applied on 16 students out of 21, as five students were not able to attend. And since the examination's dates were advanced, and the second semester of 1442 were brought to an end in response to the Royal Decree that was issued along other measures to control the Corona pandemic, it was difficult to provide alternative dates or repeat the skill and cognitive pretests or posttest. So, the experiment was limited to the number of students present at that time. 
Table 13. The coefficient of assessors' agreement on the educational program.

\begin{tabular}{lccc}
\hline \multicolumn{1}{c}{ Assessment items } & $\begin{array}{c}\text { Times of } \\
\text { agreement }\end{array}$ & $\begin{array}{c}\text { Times of } \\
\text { disagreement }\end{array}$ & $\begin{array}{c}\text { Agreement } \\
\text { coefficient }\end{array}$ \\
\hline $\begin{array}{l}\text { Drafting and clarity of } \\
\text { phrases }\end{array}$ & 10 & 0 & $100 \%$ \\
$\begin{array}{l}\text { sequencing and organizing } \\
\text { number of phrases }\end{array}$ & 10 & 0 & $100 \%$ \\
$\begin{array}{l}\text { The questionnaire included } \\
\text { the objectives of the research }\end{array}$ & 9 & 0 & $80 \%$ \\
\hline
\end{tabular}

\section{0 .Study Results and Findings}

\subsection{Verifying the Validity of the First Hypothesis}

The validity of the first hypothesis of the research which states that there is a statistically significant difference at the level $(\alpha \leq 0.05)$ between the mean scores of students in the experimental group after the application of pretests and posttests on the cognitive achievement, in favor of posttests, was tested.

To verify the validity of the first hypothesis, the researcher performed the following statistical procedures:

Calculating the averages and standard deviations of the scores of students in the experimental group after the application of pretests and posttests on the cognitive achievement and after teaching an educational program in pattern-making of children's clothing and implementing them using e-learning. The following Table 14 summarizes these results.

The results summarized in the previous table shows that there is an improvement in the performance of students in the experimental group after the application of posttests. This is proved by results of comparison between the averages and standard deviations of the students' performance in the pretests and posttests applications.

The Wilcoxon Signed Rank Test and the following Table 15 summarizes these results.

The results summarized in the previous table shows that the " $\mathrm{z}$ " value is a significant at the level (0.05); Thus, the researcher can accept the first hypothesis, which states that there is a statistically significant difference at the level ( $\alpha \leq$ 0.05 ) between the mean scores of students in the experimental group after the application of pretests and posttests on the cognitive achievement, in favor of posttests.

\subsection{Verifying the Validity of the Second Hypothesis}

The validity of the second hypothesis of the research which states that there is a statistically significant difference at the level $(\alpha \leq 0.05)$ between the mean scores of students in the experimental group after the application of pretests and posttests on skill performance, in favor of posttests, was tested. 
Table 14. Averages and standard deviations of the scores of students in the experimental group after the application of pretests and posttests on the cognitive achievement.

\begin{tabular}{ccc}
\hline Performance type & Average & Standard deviation \\
\hline Pretests & 6.62 & 1.54 \\
Posttests & 12.37 & 0.957 \\
\hline
\end{tabular}

Table 15. The value of " $z$ " and its statistical significance for the difference between the mean scores of students in the experimental group following the application of pretests and posttests of the cognitive achievement.

\begin{tabular}{cccccc}
\hline $\begin{array}{c}\text { Binary correlation } \\
\text { coefficient of ranks } \\
(\text { effect size }=\text { rprb) }\end{array}$ & $\begin{array}{c}\text { level of } \\
\text { significance }\end{array}$ & $\begin{array}{c}\text { statistical } \\
\text { "z” }\end{array}$ & $\begin{array}{c}\text { Total } \\
\text { Ranks }\end{array}$ & $\begin{array}{c}\text { Average } \\
\text { Ranks }\end{array}$ & Signs Rank \\
\cline { 2 - 5 } $\begin{array}{c}\text { S.00 } \\
\text { Very strong }\end{array}$ & Significant* & 3.537 & 0.00 & 0.00 & Negative \\
\hline
\end{tabular}

*at 0.05 level.

To verify the validity of the second hypothesis, the researcher performed the following statistical procedures:

Calculating the averages and standard deviations of the scores of students in the experimental group following the application of pretests and posttests on the skill performance, and after teaching an educational program in pattern-making of children's clothing and implementing the designs, using e-learning. The following Table 16 summarizes these results.

The results summarized in the previous table show that there is an improvement in the performance of students in the experimental group in the posttests application, and this can be proved by the results of comparison between the averages and standard deviations of the students' performance in the pretests and posttests applications.

The Wilcoxon Signed Rank Test and the following Table 17 summarizes these results.

The results summarized in the previous table shows that the " $\mathrm{z}$ " value is a significant at the level (0.05); Thus, the researcher can accept the second hypothesis, which states There is a statistically significant difference at the level ( $\alpha \leq$ 0.05 ) between the mean scores of students in the experimental group after the application of pretests and posttests on skill performance, in favor of posttests.

\subsection{Verifying the Validity of the Third Hypothesis}

The validity of the third hypothesis of the research which states that there is a statistically significant difference at the level (0.05) between the frequencies and percentages of the levels of the attitude scale of students with severe hearing impairment towards learning pattern-making of children's clothing, using e-learning (strongly agree, agree, neutral, disagree, strongly disagree), was tested.

To verify the validity of the third hypothesis, the researcher analyzed the results of the levels of the students' attitude scale towards an educational program 
Table 16. Averages and standard deviations of the scores of students in the experimental group following the application of pretests and posttests on skill performance.

\begin{tabular}{llll}
\hline \multicolumn{1}{c}{$\begin{array}{c}\text { Components of skill } \\
\text { performance }\end{array}$} & $\begin{array}{c}\text { Performance } \\
\text { type }\end{array}$ & Average & $\begin{array}{c}\text { Standard } \\
\text { deviation }\end{array}$ \\
\hline $\begin{array}{l}\text { The basic divisions } \\
\text { of the pattern }\end{array}$ & $\begin{array}{l}\text { Pretests } \\
\text { Pretests }\end{array}$ & 1.38 & 0.62 \\
\hline pattern drawing & Pretests & 9.62 & 0.50 \\
\hline $\begin{array}{l}\text { Data writings within the } \\
\text { borders of the pattern }\end{array}$ & Pretests & 17.88 & 2.10 \\
\hline $\begin{array}{l}\text { Color the basic lines of the } \\
\text { pattern as per the colors } \\
\text { assigned to them }\end{array}$ & Pretests & 8.88 & 2.31 \\
\hline & Pretests & 15.88 & 2.53 \\
Skill performance (as a whole) & Posttest & 8.19 & 2.09 \\
\hline
\end{tabular}

Table 17. The value of " $\mathrm{z}$ " and its statistical significance for the difference between the mean scores of students in the experimental group following the application of pretests and posttests on skill performance.

\begin{tabular}{|c|c|c|c|c|c|c|}
\hline $\begin{array}{c}\text { Test } \\
\text { Component }\end{array}$ & $\begin{array}{l}\text { Ranks of } \\
\text { Signs }\end{array}$ & $\begin{array}{l}\text { Average } \\
\text { Ranks }\end{array}$ & $\begin{array}{c}\text { Average } \\
\text { Ranks }\end{array}$ & $\begin{array}{l}\text { Statistical } \\
\text { " z" }\end{array}$ & $\begin{array}{c}\text { level of } \\
\text { significance }\end{array}$ & $\begin{array}{c}\text { Binary } \\
\text { correlation } \\
\text { coefficient of } \\
\text { ranks } \\
\text { (effect size = } \\
\text { rprb) }\end{array}$ \\
\hline $\begin{array}{l}\text { The } \\
\text { basic divisions } \\
\text { of the pattern }\end{array}$ & $\begin{array}{l}\text { Negative } \\
\text { Positive }\end{array}$ & 8.00 & $\begin{array}{c}0.00 \\
120.00\end{array}$ & 3.542 & significant ${ }^{\star}$ & $\begin{array}{c}1.00 \\
\text { very strong }\end{array}$ \\
\hline $\begin{array}{l}\text { Pattern } \\
\text { drawing }\end{array}$ & $\begin{array}{l}\text { Negative } \\
\text { Positive }\end{array}$ & 8.50 & $\begin{array}{c}0.00 \\
1.6 .00\end{array}$ & 3.526 & significant ${ }^{\star}$ & $\begin{array}{c}1.00 \\
\text { very strong }\end{array}$ \\
\hline $\begin{array}{l}\text { Data writings } \\
\text { within the } \\
\text { borders of } \\
\text { the pattern }\end{array}$ & Negative & 0.00 & $\begin{array}{c}0.00 \\
136.00\end{array}$ & 3.540 & significant $^{*}$ & $\begin{array}{c}1.00 \\
\text { very strong }\end{array}$ \\
\hline $\begin{array}{l}\text { Color the basic } \\
\text { lines of the } \\
\text { pattern as per } \\
\text { the colors } \\
\text { assigned to } \\
\text { them }\end{array}$ & Negative & 0.00 & 136.00 & 3.529 & significant $^{*}$ & $\begin{array}{c}1.00 \\
\text { very strong }\end{array}$ \\
\hline $\begin{array}{c}\text { Skill } \\
\text { performance } \\
\text { (as a whole) }\end{array}$ & Negative & 0.00 & 136.00 & 3.525 & significant ${ }^{*}$ & $\begin{array}{c}1.00 \\
\text { very strong }\end{array}$ \\
\hline
\end{tabular}

*at 0.05 level. 
in pattern-making of children's clothing using e-learning, using 5-Point Likert Scale (strongly agree, agree, neutral, disagree, strongly disagree). The frequencies, percentages and chi square testvalue were calculated to find out the significance of the differences between the levels of the students' attitudes towards an educational program in pattern-making of children's clothing using e-learning.

The results showed the significance of the differences between the levels of the students' attitudes towards an educational program in pattern-making of children's clothing using e-learning in favor of "strongly agree", due to a significant Chi-squared value. Thus, the researcher can accept the third hypothesis.

\subsection{Verifying the Validity of the Fourth Hypothesis}

The validity of the fourth hypothesis of the research which states that there is a positive significant correlation between the scores of students in the experimental group in the cognitive achievement posttests and their scores on the skill performance test, was tested.

To verify the validity of the fourth hypothesis, the researcher calculated the Pearson correlation coefficient between the scores of the students in the experimental group in the cognitive achievement posttests, and their scores on the skill performance posttests.

The results indicated that there is a significant positive correlation at the 0.01 level between the scores of the experimental group students in the cognitive achievement posttests and their scores on the skill performance posttests, where the value of " $\mathrm{t}$ " was $\left(0.239^{\star}\right)$. Thus, the fourth hypothesis of the research can be accepted.

\subsection{Verifying the Validity of the Fifth Hypothesis}

The validity of the fifth hypothesis, which states that providing an educational program in pattern-making of children's clothing for students with severe hearing impairment using e-learning, can be effective in developing cognitive achievement and skill performance, according to Blake Modified Gain Ratio was tested.

The researcher performed the following statistical procedures:

The averages scores of students in the experimental group for the cognitive achievement and skill performance posttests and pretests were calculated.

The value of Modified Gain Ratioin the cognitive achievement test for the students in the experimental group was (1.190), which is an acceptable value because it is greater than "integer one". Therefore, it can be said that an educational program in pattern-making of children's clothing for students with severe hearing impairment using e-learning, has an acceptable degree of effectiveness with regard to the development of cognitive achievement (It achieves greater than (1.02) in Blake Modified Gain Ratio).

The value of Modified Gain Ratioin the skill performance test for the students in the experimental group was (1.136), which is an acceptable value because it is 
greater than "integer one". Therefore, it can be said that an educational program in pattern-making of children's clothing for students with severe hearing impairment using e-learning, has an acceptable degree of effectiveness with regard to the development of skill performance (It achieves greater than (1.02) in Blake Modified Gain Ratio).

Based on the above, it is possible to accept the fifth hypothesis of the research hypotheses, as per Blake Modified Gain Ratio.

\section{Study Recommendations}

In light of the mentioned results, the study recommends the following:

- Implementing computer-based educational programs for the rest of the fashion and textile courses so that they are designed in a way that suits the characteristics of students with severe hearing impairment, acknowledging their capabilities that can be exploited by providing a learning environment appropriate for their educational characteristics.

- Investing in the positive attitudes for female students and faculty members towards e-learning, and developing plans and programs to benefit from these attitudes, and providing training programs in the field of e-learning to both students and faculty members.

- In light of Corona Pandemic, highlighting the need to pay attention to introducing e-learning in academic university, and adopt it as a method of teaching, and to prepare the academic curricula in a manner that is appropriate and in line with e-learning systems.

- Providing an appropriate educational structure for the application of e-learning at universities, and removing all human, material and technical obstacles that prevent its application in various stages and fields within the educational system.

- Instructing the research centers to provide production and programming services that serve researchers and faculty members in converting academic curriculum into electronic systems.

\section{Conflicts of Interest}

The authors declare no conflicts of interest regarding the publication of this paper.

\section{References}

Al-Hawli, K. A. (2010). A Competency-Based Program to Develop the Skill of Designing Educational Programs for Teachers of Technology. Master's Thesis, Gaza: College of Islamic Education.

Al-Jabr, I. A.-A. (2019). Challenges Facing Female Teachers of Deaf Hearing-Impaired Students in Using Modern Technologies at the Secondary Stage. The Arab Journal of Disability and Gifted Sciences, 9.

Al-Khasawneh, M. A., Al-Khawaldeh, M. A. R., \& Abu Maryam, A. R. (2010). Introduction to Hearing Impairment (I 1). Dar Al-Andalus for Publishing and Distribution. 
Al-Nimr, I. (2015). Hearing Problems, Introduction to Hearing Impairment. Al-Yazuri Scientific Publishing and Distribution House.

Al-Shehri, F. A. A. (2019). Design a Media-Based Program to Teach Fashion Design to the Hearing Impaired. International Designs Magazine, 1, 321.

Ayasra, W. (2017). Education and E-Learning Technology (I) 1. Dar Osama for Publishing and Distribution.

Elgazzar, A. E. (2014). Developing E-Learning Environments for Field Practitioners and Developmental Researchers: A Third Revision of an ISD Model to Meet E-Learning and Distance Learning Innovations. Open Journal of Social Sciences, 2, 29-37. https://doi.org/10.4236/jss.2014.22005

Fares, N. M., \& Ismail, A. R. M. (2017). E-Learning: Innovations in Theory and Strategy (I 1). The World of Books.

Hanafi, A. A. R. Al-N. (2009). Supportive Technology and Its Role in Activating the Goals of Educating Deaf Students in Integration Institutes and Programs "Analytical Study". Seventh International Conference: Education at the Beginning of the Third Millennium.

Hanafi, A. A. R. Al-N. (2018). For Higher Education of People with Disabilities: Reality, Requirements, and the Role of Support Services for People with Hearing Disabilities as a Model. Journal of the Faculty of Education, 33.

Jabr, J. (2012). The Importance of E-Learning in Supporting Society. Al-Adab Journal, 102, 501-513.

Ministry of Education (2021). General Education, Equality in Education for Persons with Disabilities Date of Entry.

https://www.moe.gov.sa/ar/PublicEducation/Pages/Equality_in_edu_disabilities.aspx 